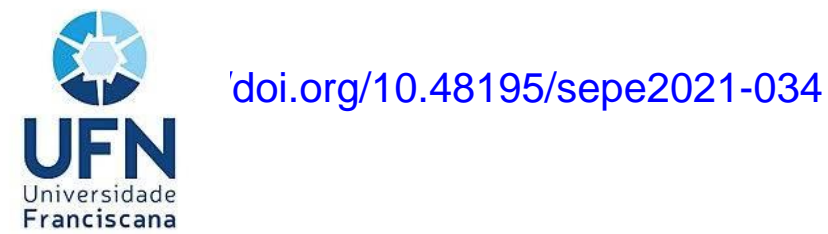

Curso de Graduação em Enfermagem

Disciplina: Temáticas Emergentes em Saúde

\title{
TECNOLOGIA EDUCACIONAL PARA A PREVENÇÃO DA VIOLÊNCIA CONTRA MULHERES
}

Gabriélli dos Santos Rosa; Carolina Araujo Londero; Stephani Sortica Fantinel; Juliana de

Avila Fuhr; Martha Helena Teixeira de Souza

\section{RESUMO}

O presente trabalho trata-se de uma atividade proposta na disciplina de Temáticas Emergentes em Saúde, sendo cursada no sétimo semestre do curso de Graduação em Enfermagem da Universidade Franciscana/ UFN, no primeiro semestre do ano de 2021. Na atividade a professora tinha como tema disparador a Violência de Gênero, reforça-se que por conta da pandemia, todas as atividades estão sendo realizadas de forma online. Busca-se elucidar de que forma será criado uma cartilha educativa, justificado pela necessidade de abordar a temática de violência contra mulher no âmbito escolar e tendo como método uma revisão de literatura com recorte temporal de dez anos e autores que falassem a respeito da temática. O fenômeno da violência contra mulher no contexto brasileiro, está presente em inúmeros cenários, tornandose a partir da última década um problema de saúde pública. Considere-se que a cartilha educativa produzida tem como objetivo contribuir efetivamente para compreensão dos tipos de violência, buscando a ampliação do debate da temática.

PALAVRAS-CHAVE: Adolescentes; Educação; Saúde; Violência;

\section{INTRODUÇÃO}

O fenômeno da violência contra mulher no contexto brasileiro, está presente em inúmeros cenários, tornando-se a partir da última década um problema de saúde pública. Nesse sentido, há 15 anos atrás fazia-se vigente a Lei de $n^{\circ} 11.340$ de 07 de agosto de 2006, popularmente conhecida como Lei Maria da Penha, a qual ampliou os mecanismos para prevenir e refrear a violência familiar e doméstica contra a mulher (BRASIL, 2006).

Os pressupostos da Lei afirmam que todas as mulheres, independentemente de fatores socioeconômicos e socioculturais, asseguram estratégias e oportunidades a fim da preservação da integridade mental e física. Atrelado a isso, a Constituição Federal de 1988, garante 
igualdade entre homens e mulheres, sendo este documento o primeiro a estabelecer tais garantias de direitos (FEDERAL, 1988).

Refletindo sobre as implicações da pandemia na vida das mulheres, constatou-se segundo o Anuário Brasileiro de Segurança Pública, que os casos de feminicídios tiveram um crescimento no primeiro semestre de 2020, em relação ao mesmo período do ano anterior, ademais preocupa-se que as denúncias tiveram uma queda também (BUENO et al, 2020). O dado que foi apresentado, qualifica-se como um disparador para as questões sociais, as quais a pandemia está correlacionada.

Uma pesquisa realizada no ano de 2013 demonstrou que $43 \%$ das adolescentes a partir de 15 anos declararam ter sofrido violência praticada por um homem, sendo um membro da família ou parceiro, um terço admitiu ter sofrido alguma forma de violência física, $13 \%$ sexual e $27 \%$ psicológica (SANTOS et al, 2020). Percebendo que os casos de violências se iniciam na adolescência, a cartilha será realizada para auxiliar estas meninas a identificar como elas ocorrem no cotidiano.

O processo de desenvolvimento, dos adolescentes, caracteriza-se como um período propício para ações de prevenção e promoção da saúde, pois durante essa fase os hábitos ainda podem ser moldados com mais facilidade, portanto a realização da ação na escola poderá impactar de forma positiva estes jovens (TAQUETTE, 2015).

Nesses processos de violência, que por vezes iniciada no desenvolvimento, expandiuse as políticas públicas voltadas para a proteção desses cidadãos, sobretudo com o advento do Estatuto da Criança e do Adolescente (ECA), legitimado pela Lei no 8.069 de 13 de junho de 1990, esse considera criança até doze anos de idade incompletos e adolescente a partir dos 12 anos de idade completos até 18 anos de idade, podendo ser aplicado até os 21 anos de idade (BRASIL, 1990). Desta forma, a partir de uma breve busca na literatura percebeu-se que os jovens tornam-se vulneráveis para o início de atos violentos.

Nessa continuidade, ainda no que tangem à aspectos legais, uma das mais recentes normativas está a Lei 13.010 de 26 de junho de 2014, também conhecida como Lei da Palmada ou Lei do Menino Bernardo, dispõe sobre os cuidados e a educação dos menores de idade, sem usar do castigo físico, ou seja, não usar da força física em caráter punitivo que possa gerar lesões e/ou sofrimento físico. Além disso, pressupõe sobre a não utilização de tratamentos cruéis ou que degradem o sujeito, não sendo permitido ridicularizar, humilhar ou ameaçar gravemente adolescentes e crianças (BRASIL, 2014).

Com o explanado busca-se elucidar de que forma será criado um material didático, justificado pela necessidade de abordar a temática de violência contra mulher no âmbito escolar, 
visto que segundo a literatura científica as ocorrências de violência se iniciam na adolescência. Salienta-se que em consonância com a Política Nacional de Atenção Integral à Saúde da Mulher busca-se promover a atenção integral para as adolescentes em situação de violência (BRASIL, 2009).

\section{MATERIAL E MÉTODOS}

Trata-se de uma atividade proposta na disciplina de Temáticas Emergentes em Saúde, sendo cursada no sétimo semestre do curso de Graduação em Enfermagem da Universidade Franciscana/ UFN, no primeiro semestre do ano de 2021. Na atividade proposta pela professora tinha como tema disparador a Violência de Gênero, reforça-se que por conta da pandemia, todas as atividades estão sendo realizadas de forma online.

Tendo isto em vista, foi criada uma cartilha educativa para adolescentes, abordando os tipos de violência e como elas se apresentam no cotidiano, bem como um levantamento de dados nas bases de dados Scielo e Lilics, com um recorte temporal de dez anos e autores que conversassem com a temática. O material informativo foi construído na plataforma digital canva, disponibilizada por meio de um link de acesso online, o qual será compartilhado com público-alvo, adolescentes de 14 até 18 anos, de uma escola de Educação Básica de um município de médio porte da região central do Rio Grande do Sul.

No primeiro momento mostraremos o material para a equipe diretiva da instituição, e posteriormente apresentada aos estudantes, salientado o objetivo principal que é abordar a temática da violência contra a mulher no ambiente escolar. A cartilha será utilizada como uma metodologia ativa, visando exemplificar para adolescentes as nuances de como a violência começa e como compreendê-la no cotidiano, para além de reforçar a necessidade da denúncia.

Desta forma elucida-se que a igualdade afirmada pelo pedagogo Paulo Freire como condição de uma educação libertadora para a qual deve-se aceitar e respeitar as diferenças, nesse contexto a violência contra a mulher (KOHAN, 2019).

\section{RESULTADOS E DISCUSSÕES}

Elucidarmos a atividade em dois tópicos, sendo eles "Políticas Públicas X Adolescência”, o qual apresentará um levantamento bibliográfico que se aproximou do tema e "A educação continuada por meio de uma cartilha educativa", estes propõem a reflexão sobre o impacto social do produto técnico, os quais serão debatidos a seguir. 


\section{Políticas Públicas X Adolescência}

De acordo com a Organização Mundial da Saúde (OMS), a adolescência compreende dos 10 aos 19 anos, sendo dividida em fase inicial e a fase final (BRASIL, 2017). Alguns pesquisadores indicam um conceito de adolescência com vários sentidos, levando em conta as mudanças sociais, bem como a evolução de pensamento, atrelada às significações da sociedade às diversas realidades possíveis (ROSSI et al, 2019).

O ECA apresenta um avanço legal e social, das medidas que estende a todas as crianças e adolescentes a proteção integral e preferencial, colocando estes como sujeitos de direitos, estes que por sua vez estão presentes na constituição federal de 1988 (AZEVEDO et al, 2017).

No que tange o acesso aos serviços de saúde, constatou-se que no caso da faixa etária que compreende a adolescência, fica evidente uma fraqueza do sistema de saúde, a partir de uma visão do Sistema Único de Saúde (SILVA et al, 2019). Desta forma, ocorre a necessidade de fortalecer o vínculo profissional com os jovens, cita-se como exemplos ações como o Programa Saúde na Escola, instituído pelo governo federal em 2007.

Nesse contexto, a atuação de profissionais e acadêmicos de cursos da saúde torna-se importante, pela complexidade de fatores que envolve as ocorrências violência. Segundo Zancan (2013) às causas de ações violentas são multifatoriais, como abuso de substâncias lícitas e ilícitas, como álcool e drogas, ciúmes, fator que eleva o aumento de tensão no casal, demonstrando caráter de dominação e posse, além de um ambiente familiar com histórico de violência presenciada ou sofrida na infância e a vulnerabilidade de gênero.

\section{A educação continua por meio de uma cartilha educativa}

Considera-se o material didático disposto de forma online, pelo impacto do Covid-19, pois as implicações perpetuam muito além da doença em si, o caos gerado pela pandemia, perpassa questões sanitárias e sociais, afetando grupos sociais como um todo, as desigualdades entre mulheres e homens podem ser determinantes neste processo (CAMPOS et al, 2020). A partir de uma retomada histórica, percebeu-se que em outras crises sociais e econômicas, reduziram-se o acesso aos serviços de atenção à violência de gênero (HALL et al, 2020).

Refletindo sobre isso a cartilha foi construída com uma fácil leitura, a fim de apresentar os tipos de violência e os possíveis canais de denúncia, partindo da temática de que a educação continuada em saúde é de fundamental importância para o desenvolvimento saudável. Além disso, salienta-se que violência contra mulher segundo a OMS é um problema de saúde pública, o qual afeta nossas relações sociais. 
Em uma pesquisa realizada em 2015 constatou-se que os pais sentem dificuldade para falar com os filhos sobre violência e sexualidade, e se fazem de forma sutil (NERY et al, 2015). A cartilha foi construída levando isso em conta, utilizou-se recursos visuais para elucidar, com o objetivo de ampliar e questionar a forma que abordamos atos violentos, ao longo ainda reforça a importância de "meter a colher", pois socialmente há uma corrente de pensamento em que "em briga de marido e mulher, não se mete colher".

Ressalta-se ainda que está garantido pela Constituição Federal (1988), em seu artigo $5^{\circ}$ o direito à vida, à liberdade, à igualdade, desta forma deve ser refutado todo e qualquer ato de violência contra a mulher.

\section{CONSIDERAÇÕES FINAIS}

Considere-se que o produto tecnológico produzido irá contribuir efetivamente para compreensão dos tipos de violência, buscando a ampliação do debate da temática, sabendo que a partir dos achados na literatura não há uma conversa ampla sobre o tema no âmbito familiar. Sendo a cartilha possui uma fácil linguagem para a ampliação do diálogo para o enfrentamento da violência, mesmo no momento pandêmico.

Para além disso, reforça-se que os grandes índices de violência contra as mulheres não são apenas resultado da pandemia, mas sim de uma construção social, que reforça uma enorme desigualdade de gênero, perpassando gerações. A literatura científica correlaciona as bases sociais de poder, como um dos pontos chaves de atos violentos, constituindo relações desiguais de poder, ou seja, constitui um tipo de violência motivada pela condição desigual de sexo, a qual tende a começar no universo familiar (SANTOS et al, 2020).

\section{REFERÊNCIA}

AZEVEDO, Cinthya Rebecca Santos; AMORIM, Tâmara Ramalho de Sousa; ALBERTO, Maria de Fatima Pereira. Adolescência e ato infracional: violência institucional e subjetividade em foco. Psicologia: Ciência e Profissão, v. 37, n. 3, p. 579-594, 2017.

BRASIL. LEI No 11.340, 7 de Agosto de 2006. Brasília, 2006.

BRASIL. Ministério da Justiça. Lei n 8.609, de 13 de julho de 1990. Brasília, 1990. 
BRASIL. Ministério da Saúde (MS). Secretaria de Atenção à Saúde. Departamento de Ações Programáticas Estratégicas. Política nacional de atenção integral à saúde da mulher: princípios e diretrizes. Brasília: Editora do Ministério da Saúde; 2009.

BRASIL. Ministério da Saúde. Departamento de Informática do Sistema Único de SaúdeDATASUS. Sistema de Informações de Mortalidade -SIM. Brasília, 2019.

BRASIL. Ministério da Saúde. Secretaria de Atenção à Saúde. Departamento de Ações Programáticas e Estratégicas. Proteger e cuidar da saúde de adolescentes na atenção básica/ Ministério da Saúde, Secretaria de Atenção à Saúde, Departamento de Ações Programáticas e Estratégicas. - 2. ed. - Brasília : Ministério da Saúde, 2018.

CAMPOS, Brisa; TCHALEKIAN, Bruna; PAIVA, Vera. Violência contra a mulher: vulnerabilidade programática em tempos de sars-Cov-2/covid-19 em São Paulo. Psicologia \& Sociedade, v. 32, 2020.

FEDERAL, Senado. Constituição. Brasília (DF), 1988.

FÓRUM BRASILEIRO DE SEGURANÇA PÚBLICA - FBSP. Anuário Brasileiro de Segurança Pública. Edição XIII. São Paulo, 2019.

HALL, Kelli Stidham et al. Centring sexual and reproductive health and justice in the global COVID-19 response. The lancet, v. 395, n. 10231, p. 1175-1177, 2020.

KOHAN, Walter Omar. Paulo Freire e o valor da igualdade em educação. Educação e Pesquisa, v. 45, p. e201600-e201600, 2019.

ROSSI, Lívia Martins et al. Crise e saúde mental na adolescência: a história sob a ótica de quem vive. Cadernos de Saúde Pública, v. 35, 2019.

SANTOS, Ione Barbosa dos et al. Violência contra a mulher na vida: estudo entre usuárias da Atenção Primária. Ciência \& Saúde Coletiva, v. 25, p. 1935-1946, 2020. 
TAQUETTE, Stella R. Violência contra a mulher adolescente-revisão de estudos epidemiológicos brasileiros publicados entre 2006 e 2011. Adolescência e Saúde, v. 12, n. 1, p. 66-77, 2015.

ZANCAN, Natália; WASSERMANN, Virginia; LIMA, Gabriela Quadros de. A violência doméstica a partir do discurso de mulheres agredidas. Pensando Famílias, Porto Alegre, v. 17, n. 1, p. 63-76, jul. 2013. 